\title{
Effects of Recycled Steel and Polymer Fibres on Explosive Fire Spalling of Concrete
}

\author{
Fabio P. Figueiredo* (D), Shan-Shan Huang, Kypros Pilakoutas, and Ian \\ Burgess, Department of Civil and Structural Engineering, University of \\ Sheffield, Sir Frederick Mappin Building, Mappin Street, Sheffield S1 3JD, \\ $U K$ \\ Harris Angelakopoulos, Twincon Ltd, 40 Leavygreave Road, Sheffield S3 7RD, \\ $U K$
}

Received: 21 December 2017/Accepted: 25 January 2019

\begin{abstract}
Modern high-performance concrete, increasingly used in tunnels and other important infrastructure, is susceptible to explosive fire-induced spalling. To prevent fire spalling, modern codes recommend the use of small quantities (e.g. $2 \mathrm{~kg} / \mathrm{m}^{3}$ as recommended by the Eurocodes) of polypropylene fibres in the concrete mix. This paper presents an experimental study investigating, the effect of cleaned recycled fibres extracted from end-of-life tyres on the explosive fire-induced spalling of concrete. This paper presents 24 spalling tests, indicating that recycled tyre polymer fibres, at dosages equal to or larger than $2 \mathrm{~kg} / \mathrm{m}^{3}$, might help prevent fire spalling. Recycled tyre steel fibres also show the potential of preventing fire spalling damage by keeping spalled concrete attached to the heated surface, thus protecting the main steel reinforcement. The use of these fibres might lead to safe and sustainable fire spalling mitigation solutions.
\end{abstract}

Keywords: Spalling, Concrete, Tyre, Polymer fibre, Recycled tyre steel fibre, Recycled tyre polymer fibre

\section{Introduction}

Despite the common perception that concrete is fireproof, it is prone to fire-induced spalling: the explosive loss of surface concrete when exposed to rapidly rising temperatures. The problem of fire-induced spalling in concrete-lined tunnels is a particularly relevant issue at present. Fire-induced explosive spalling is mainly caused by the combined effect of differential thermal stresses and excessive pore pressure developed behind the exposed concrete surface. This explosive fire-induced spalling can lead to a reduction of the cross-sectional areas of structural elements and cause loss of thermal protection to steel reinforcement, both of

\footnotetext{
* Correspondence should be addressed to: Fabio P. Figueiredo, E-mail: fabiopf@hotmail.co.uk
} 
which could significantly reduce the fire resistance of concrete structures. In recent decades, fire-induced spalling has caused huge economic losses [1]. High-performance (high-strength, self-compacting) concrete [2] is increasingly being used instead of conventional concrete, in tunnels and other major infrastructure projects. This concrete is particularly vulnerable to fire-induced spalling [3].

Due to the concern about fire spalling, much research on the use of fibres in concrete to mitigate fire-induced spalling has been conducted. It has been found that polypropylene fibres (PPF) can be effective in mitigating fire spalling [3-9]. PPF melt at about $170^{\circ} \mathrm{C}$ and vaporize at about $340^{\circ} \mathrm{C}$ and could therefore create voids which are thought to release vapour pressure. Ozawa and Morimoto [10] showed that the permeability of PPF concrete can increase by up to thirteen times after heating to $350^{\circ} \mathrm{C}$ compared to a reference plain concrete. They also concluded that increasing permeability reduces the probability of explosive spalling.

Other studies have shown that the mechanical properties of concrete are also affected by the addition of fibres. For example, by adding PPF [11-13] the compressive strength is likely to be slightly reduced, mainly due to an associated increase in voids. On the other hand, the addition of steel fibres to concrete generally increases its compressive strength at ambient temperature [14-16]. The postfire residual compressive strength of concrete decreases due to the addition of fibres, but the fracture energy is significantly higher after fire exposure than it is before heating [15]. Recently Yermak et al. [17] studied different high strength concretes $(70 \mathrm{MPa})$ consisting of different aggregate types, moisture contents, lengths and dosages of PPF and steel fibres (SF), subjected to the standard ISO 834 fire [18]. The results confirmed that PPF increase the porosity and permeability of concrete, and that steel fibres could help control crack development and prevent the occurrence of large cracks.

The effectiveness of steel and polypropylene fibres in the mitigation of fire-induced spalling depends on several factors, such as fibre content, type, diameter and length. The addition of PPF to concrete has the clear potential to prevent spalling [3-9], whilst steel fibres could have a different role, of increasing the tensile strength of the concrete, which should help to lower the risk of spalling [19, 20]. Other researchers have indicated that blending steel and polypropylene fibres can reduce the degree and severity of spalling, compared with concrete containing only PPF $[12,15]$.

Thousands of tonnes of polymer and steel fibres are generated each year in Europe alone, as by-products of recycling (mainly for recovering rubber) of end-oflife tyres. These fibres are made of very high-quality materials but are highly contaminated (with rubber) and so are mainly buried as landfill or incinerated [21, 22]. Appropriately processed steel fibres could be used in concrete, and classified steel fibres are now available commercially for use in slabs on grade and in tunnel linings [21-26]. Small quantities of recycled tyre polymer fibres have been cleaned appropriately, in the course of the EU-funded project Anagennisi [23], and have been examined for controlling shrinkage of cracks in concrete and mortars.

This paper examines the effectiveness of clean recycled tyre polymer fibres (RTPF) and clean recycled tyre steel fibres (RTSF) from end-of-life tyres in highstrength concrete for the mitigation of fire-induced spalling, on the basis that their 
properties are not very different from those of currently manufactured steel and polypropylene fibres (see detailed fibre characteristics in Sect. 2.1). The overall aim is to improve the sustainability of concrete construction by replacing virgin materials with reused materials, and at the same time to maintain or improve performance.

\section{Experimental Details}

The fire-spalling behaviour of concrete mixes using RTPF, RTSF and RTPF/ RTSF hybrids has been investigated through 24 slab tests in two series (see Table 1) under simultaneous high temperature and uniaxial compression (see Sect. 2.3 for detailed heating and loading arrangements). The specimens of Series 1 are: Plain1, the reference plain concrete mix; PF1, with $1 \mathrm{~kg} / \mathrm{m}^{3}$ RTPF; PF2, with $2 \mathrm{~kg} / \mathrm{m}^{3}$ RTPF (based on the Eurocode 2 recommended PPF dosage) and PF7, with $7 \mathrm{~kg} / \mathrm{m}^{3}$ RTPF.

The size of the Series 1 specimens was $500 \times 220 \times 100 \mathrm{~mm}$, without any steel reinforcement. Significant water/vapour escape was observed from the thinner Series 1 specimens. As tunnel linings are usually thicker than $100 \mathrm{~mm}$, in order to avoid an unrealistic amount of vapour/water escape which reduces pore pressure and spalling risk, thicker specimens were adopted in the Series 2 tests. The specimens of Series 2 include: Plain2, the reference plain concrete mix; SF40, containing $40 \mathrm{~kg} / \mathrm{m}^{3}$ RTSF; SF40PF2, containing $40 \mathrm{~kg} / \mathrm{m}^{3}$ RTSF and $2 \mathrm{~kg} / \mathrm{m}^{3}$ RTPF; SF40PF5 containing $40 \mathrm{~kg} / \mathrm{m}^{3}$ RTSF and $5 \mathrm{~kg} / \mathrm{m}^{3}$ RTPF.

The size of all Series 2 specimens was $500 \times 200 \times 200 \mathrm{~mm}$, with $\varnothing 5 \mathrm{~mm}$ steel mesh reinforcement at $50 \times 50 \mathrm{~mm}$ spacing placed at $30 \mathrm{~mm}$ front cover. The amount of steel mesh and RTSF used aims to reflect typical reinforcement in precast tunnel segments [24].

All tests were conducted in triplicate. The specimens were cured in a mist room, at $20^{\circ} \mathrm{C}$ and $80 \%$ relative humidity, for at least 28 days; they were then taken out of the mist room and stored in the laboratory, at approximately $50 \%$ relative humidity and $20^{\circ} \mathrm{C}$ temperature, for a week prior to being tested.

\subsection{Materials}

As high strength concrete is generally vulnerable to fire-induced spalling [3, 27], a C70 concrete mix was selected, details of which are summarised in Table 2.

Currently, polymer fibres extracted from tyres are too contaminated with rubber, and too agglomerated, to be re-used as a construction material. Techniques do not exist at present for removing rubber contamination and separating tangled filaments for the large-scale production of RTPF for use in concrete. During this research, a screening technique, using vibrating sieves, was developed to remove most of the rubber dust and particles. This was capable of supplying the quantity of cleaned RTPF needed for laboratory testing. Typical samples of RTSF and RTPF used in the experimental testing are shown in Fig. 1. A geometrical characterisation of RTPF showed that the fibre diameter ranged from 8.0 to $38.0 \mu \mathrm{m}$, 


\section{Table 1}

Specimen Specifications

\begin{tabular}{llcccc}
\hline & Type & Size $\mathrm{L} \times \mathrm{H} \times \mathrm{W}(\mathrm{mm})$ & $\mathrm{RTSF}\left(\mathrm{kg} / \mathrm{m}^{3}\right)$ & $\mathrm{RTPF}\left(\mathrm{kg} / \mathrm{m}^{3}\right)$ & Steel mesh $\left(\mathrm{kg} / \mathrm{m}^{3}\right)$ \\
\hline Series 1 & Plain1 & \multirow{2}{*}{$500 \times 220 \times 100$} & 0 & 0 & 0 \\
& PF1 & & 0 & 1 & 0 \\
& PF2 & & 0 & 2 & 0 \\
& PF7 & & 0 & 7 & 0 \\
Series 2 & Plain2 & $500 \times 200 \times 200$ & 0 & 0 & 123.3 \\
& SF40 & & 40 & 0 & 61.5 \\
& SF40PF2 & 40 & 2 & 61.5 \\
& SF40PF5 & & 40 & 5 & 61.5 \\
\hline
\end{tabular}

\section{Table 2}

\section{Mix Design}

\begin{tabular}{lc}
\hline Constituent & Amount $\left(\mathrm{kg} / \mathrm{m}^{3}\right)$ \\
\hline Coarse aggregate $(5 \mathrm{~mm}$ to $10 \mathrm{~mm})$ & 1281 \\
Fine aggregate $(0 \mathrm{~mm}$ to $5 \mathrm{~mm})$ & 734 \\
Cement (CEM II 52.5$)$ & 300 \\
PFA & 99 \\
Water & 168 \\
Superplasticizer (polycarboxylate) & 4 \\
\hline
\end{tabular}

and more than $80 \%$ of the fibres were shorter than $12 \mathrm{~mm}$. The melting points of these fibres ranged from 210 to $260^{\circ} \mathrm{C}$.

RTSF are irregular in shape (3-D) and vary in length and diameter. The RTSF used in this study had a fibre nominal average length of $20 \pm 2 \mathrm{~mm}$ and diameter of $0.15 \pm 0.04 \mathrm{~mm}$ [28]. The nominal tensile strength of the RTSF was $2850 \mathrm{MPa}$. For the convenience of comparison, typical manufactured steel fibres used in tunnel construction could be of $0.4 \mathrm{~mm}$ to $0.5 \mathrm{~mm}$ diameter, $35 \mathrm{~mm}$ length and $1700 \mathrm{~N} / \mathrm{mm}^{2}$ tensile strength. Manufactured monofilament polypropylene fibre could be of $4 \mathrm{~mm}$ to $30 \mathrm{~mm}$ length, $20 \mu \mathrm{m}$ to $30 \mu \mathrm{m}$ diameter and $450 \mathrm{MPa}$ tensile strength.

\subsection{Moisture Content and Compressive Strength}

Additional cubes and cylinders were cast for compressive strength tests and moisture content measurements. Concrete compressive strength was measured from $100 \mathrm{~mm}$ cubes on the day of each spalling test, following the BS EN 12390 [29] process. For each spalling test specimen, three cubes were tested.

Moisture content was measured using two different approaches. For Series 1, $100 \mathrm{~mm}$ cubes were heated in an electric oven at $110^{\circ} \mathrm{C}$ for $24 \mathrm{~h}$, just prior to each spalling test, and the weight loss due to evaporation was used to calculate the average moisture content of the test specimens. 


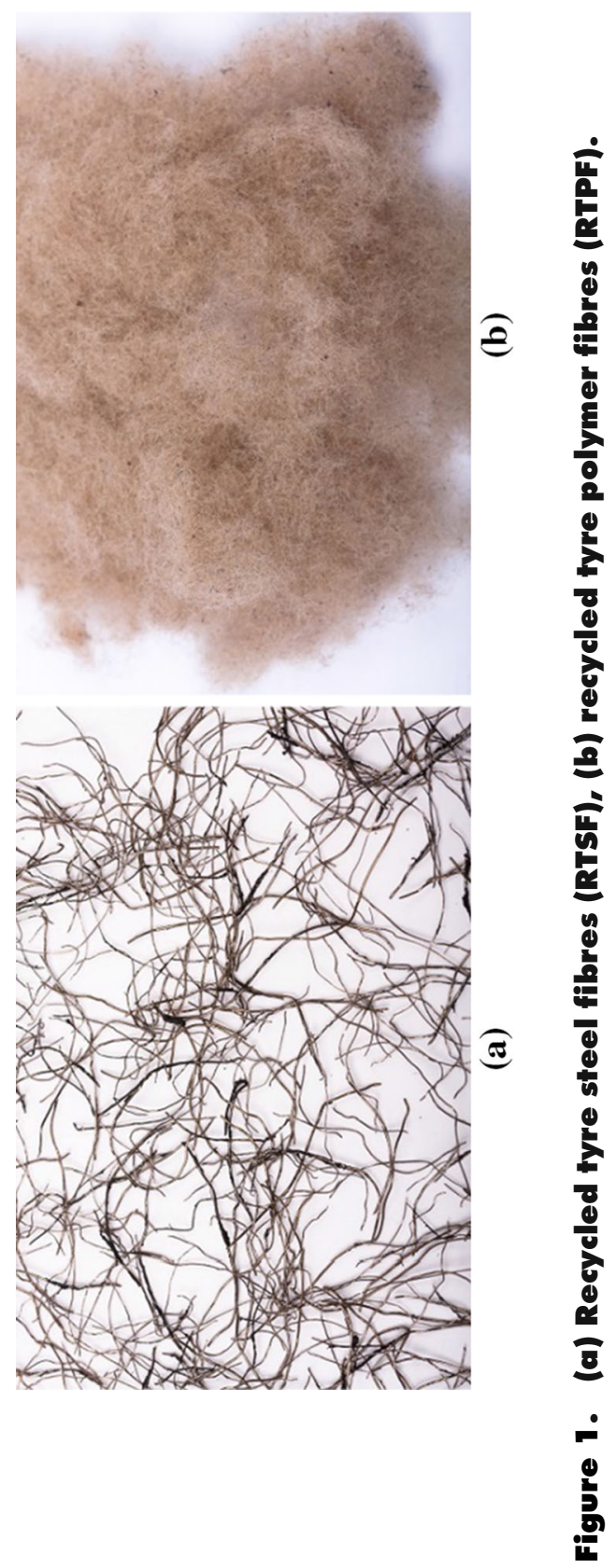




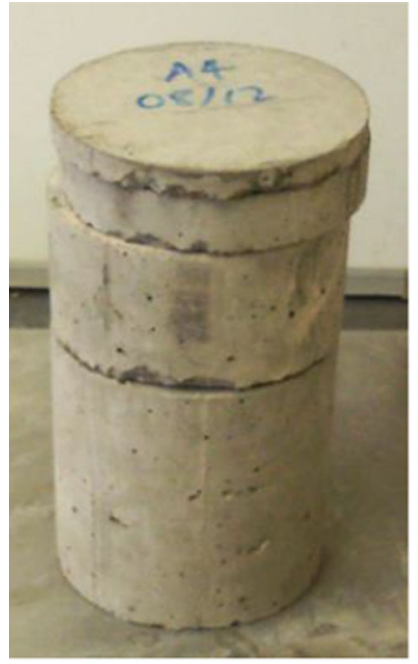

(a)

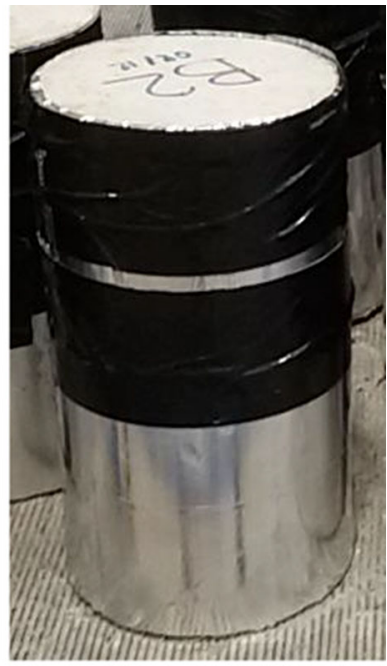

(b)

\section{Figure 2. (a) Cylinder cut into slices at heights $10 \mathrm{~mm}, 20 \mathrm{~mm}$ and $50 \mathrm{~mm}$; (b) cut cylinder wrapped with aluminium foil and plastic tapes.}

Since fire spalling happens at the surface of a concrete elements, its occurrence is at least partly dependent on the concrete moisture content near the heated surface, rather than the average moisture content within the entire volume. A different approach was adopted for Series 2 to measure the through-depth moisture content distribution, as well as its development over time. To avoid coring samples from the spalling test slabs (cooling water could affect moisture content), additional cylinders of $200 \mathrm{~mm}$ height and $100 \mathrm{~mm}$ diameter were cast. Before curing, all cylinders were cut into slices at heights of $10 \mathrm{~mm}, 20 \mathrm{~mm}$ and $50 \mathrm{~mm}$, and then reassembled to maintain the length of the moisture path [30]. The sides of the cylindrical slices were individually sealed with aluminium foil tape, and the edges of the interfaces between adjacent slices were sealed using plastic tape, as illustrated in Fig. 2. This provided the unidirectional moisture transport condition corresponding to that in the spalling test slabs. It should be noted that both the top and bottom surfaces of the cylinders were exposed to the environment. In total sixteen cylinders, four per mix (one cylinder per spalling test specimen, plus one control cylinder), were prepared. After curing in conditions identical to those of the spalling test slabs, all four pieces of one cylinder (the control specimen) from each mix were dried in the oven for $24 \mathrm{~h}$ to measure their initial moisture condition. For the rest of the cylinders, the development of moisture content over time was then monitored by weighing each slice (at each depth) daily for 27 days. 


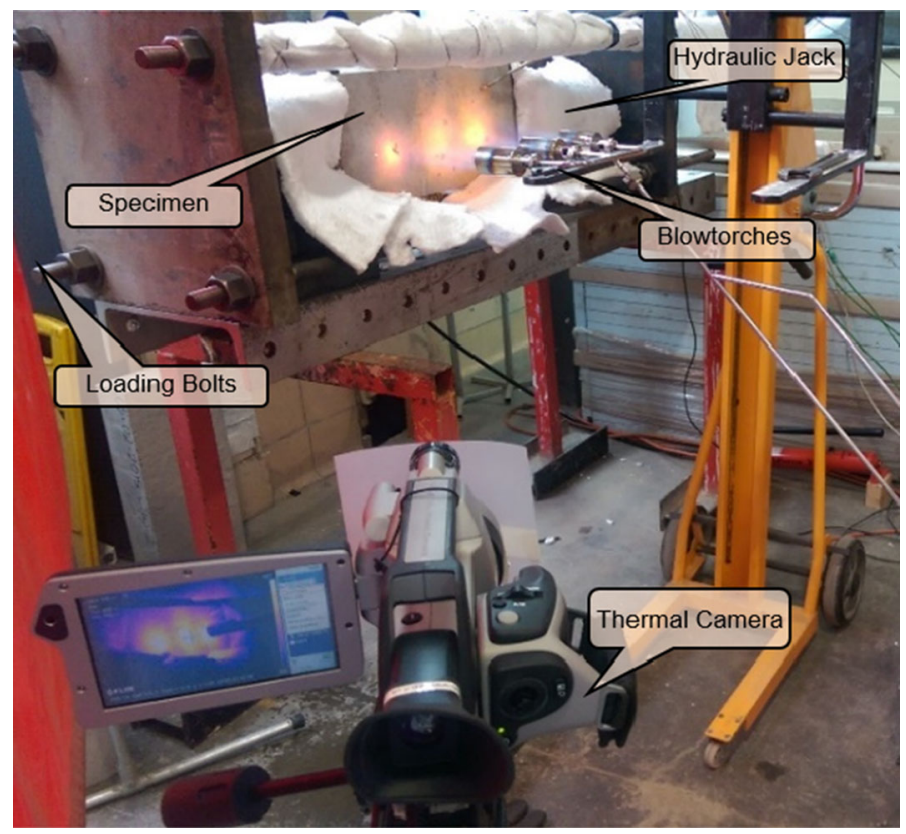

\section{Figure 3. Test setup.}

\subsection{Fire Spalling Test Setup and Measurements}

The samples were heated using a three-nozzle blowtorch, as shown in Fig. 3. Trials were conducted to determine the appropriate distance between the blowtorch heads and the heated surface of a specimen to produce an initial heating rate as close as possible to that of the large hydrocarbon pool fire curve defined in PD 7974-1 [31]. An example comparison between the time history of the maximum specimen surface temperatures and the large hydrocarbon pool fire curve is shown in Fig. 9. The distance between the blowtorch and the sample was set at $20 \mathrm{~cm}$, and this was maintained constant throughout the tests. It is worth noting that this heating method is not intended to replicate that of standard testing or that of real fires, and the heating on the heated specimen surface is not uniform. It is acknowledged that future work using heating approaches generating uniform heating comparable to standard testing is still necessary. The key purpose of this preliminary experimental study was to investigate whether the recycled fibres present any potential of reducing fire spalling risk. It is, therefore, important to ensure that the heating conditions of the specimens with and without fibres are identical.

Before heating, the specimens of Series 1 and 2 were subjected to axial average compressive stresses of $11 \mathrm{MPa}\left(16 \% f_{c u}\right)$ and $6 \mathrm{MPa}\left(9 \% f_{c u}\right)$ respectively. The loading $(250 \mathrm{kN})$ was applied using a hydraulic jack mounted between the specimen and the frame (see Fig. 3). When this force had initially been set the volume of fluid in the hydraulic system was locked, and the subsequent changes in compressive force due to thermal expansion were monitored. Since the axial stiffness 


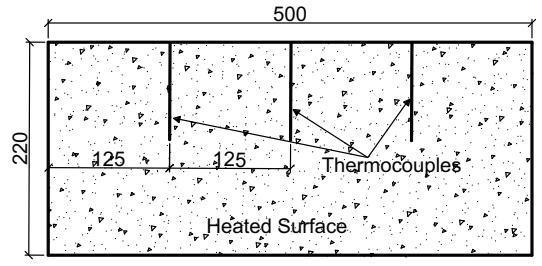

(a)

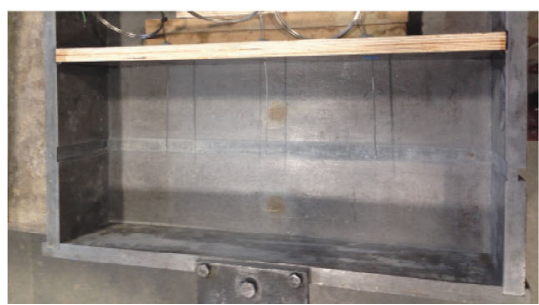

(b)

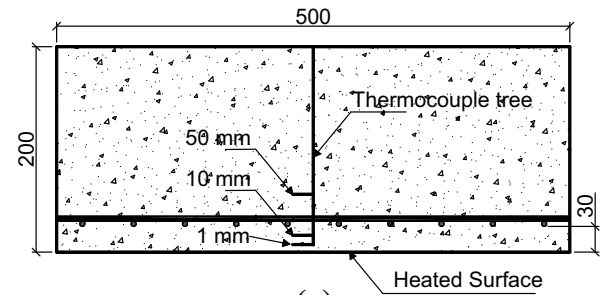

(c)

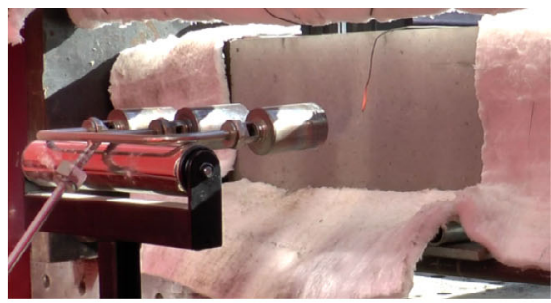

(d)

Figure 4. Thermocouple locations.

of the loading system, including the threaded rods and the hydraulic system, is at most one quarter of that of the concrete specimen, this is an arrangement which should maintain an almost-constant load.

The temperature distribution within the specimens was measured using Type $\mathrm{K}$ thermocouples, and the spalling time was recorded. For Series 1, thermocouples were cast into the slab at mid-depth $(50 \mathrm{~mm}$ from the heated surface), directly behind the centre of heating of each blowtorch head (see Fig. 4a, b). A thermal imaging camera was also used to measure the temperature distribution over the heated surface of the specimen. For Series 2, three thermocouples, tied together to make a thermocouple tree (Fig. 4c), were cast into each specimen at depths of $1 \mathrm{~mm}, 10 \mathrm{~mm}$ and $50 \mathrm{~mm}$ from the heated surface. An external thermocouple was also placed in front of the centre of the heated surface to measure the flame temperature at that location (see Fig. 4d).

\section{Results and Discussion}

Table 3 summarises the moisture content and compressive strength of each of the test specimens, as well as their spalling test results. The "Spalling time" refers to the time in heating at which a specimen initially experienced explosive fire-induced spalling. "Max spalling depth" is the depth of spalling at the most severely spalled position. "Total weight loss" is the difference between the weights of the specimen before and after the test, and "concrete loss" is the weight of the spalled concrete pieces collected after testing. It should be noted that PF2-1 failed during a trial 


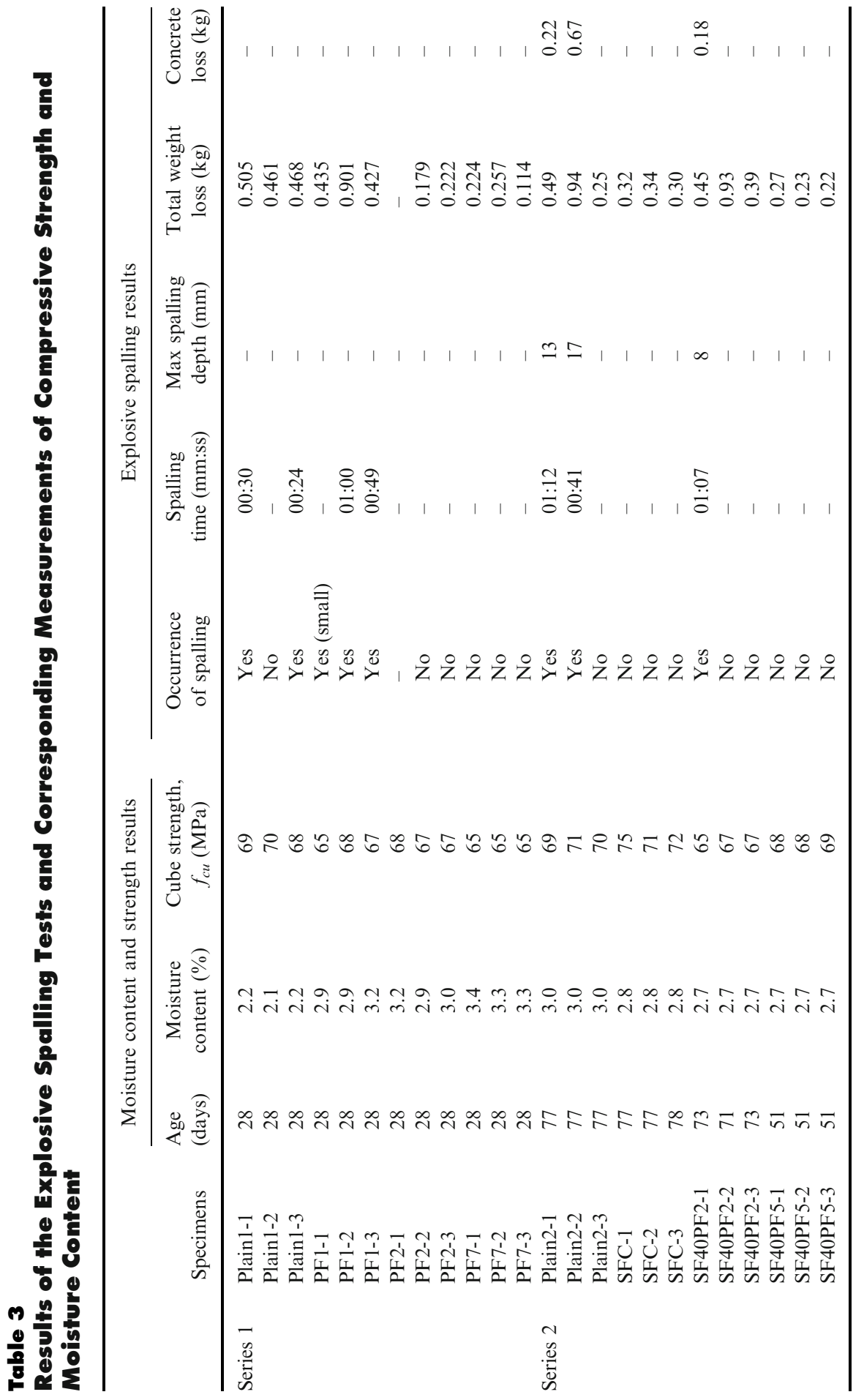




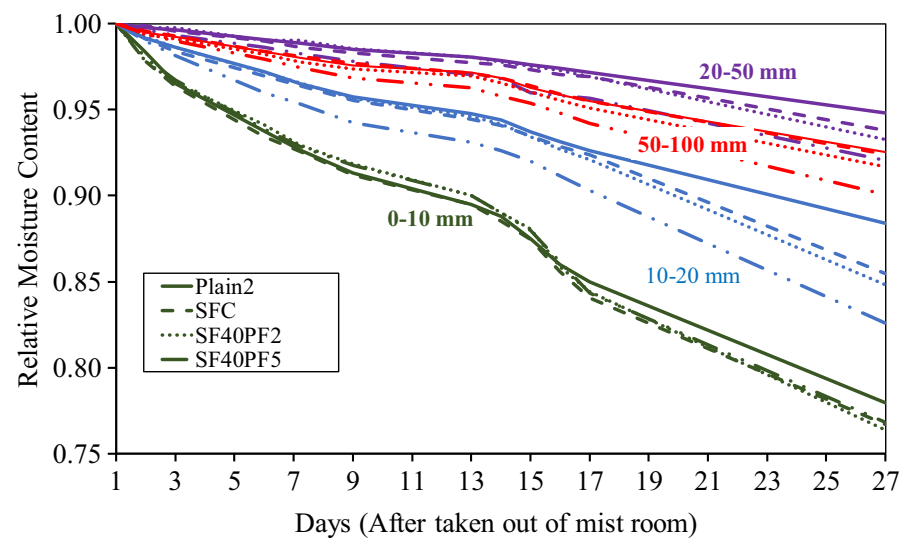

\section{Figure 5. Normalised moisture content profile of concrete slices of different thickness.}

room-temperature loading test, and that the spalling depth and concrete loss of Series 1 tests were unavailable.

\subsection{Moisture Content}

Moisture content is an important factor affecting the occurrence of fire-induced spalling. Eurocode 2 (EC2) states that explosive spalling is unlikely to occur when the moisture content of concrete is less than $3 \%$ by weight for concrete grades below C80, although it is recognised that the in-service moisture content of concrete in structures is not well known. The specimens' moisture content was measured at the time of testing. The average moisture content of specimens was between $2.12 \%$ and $3.33 \%$ by mass. However, most of the spalled specimens had moisture contents below 3\%, indicating that the EC2 threshold might lead to unsafe design.

The relative moisture content profiles for specimens of Series 2 are shown in Fig. 5. The values presented are normalised as proportions of the moisture content on Day 0 to quantitatively compare the rate of moisture loss of the various concrete slices. As expected, the greatest moisture loss was experienced by the slice nearest to the surface. Furthermore, for any given depth, more moisture was lost by the specimens with fibres than by the plain concrete specimens. This confirms that these fibres increase the connectivity of pores in concrete, facilitating the escape of vapour.

\subsection{Compressive Strength}

The average cube compressive strengths of the plain concrete specimens Plain1 and Plain2 were found to be $69 \mathrm{MPa}$ and $70 \mathrm{MPa}$, respectively (see Table 3). Previous research [32] had reported that the addition of PPF could affect the workability of fresh concrete, introduce voids and lower the strength of the hardened concrete. However, the mix adopted in this research was designed to be self-com- 


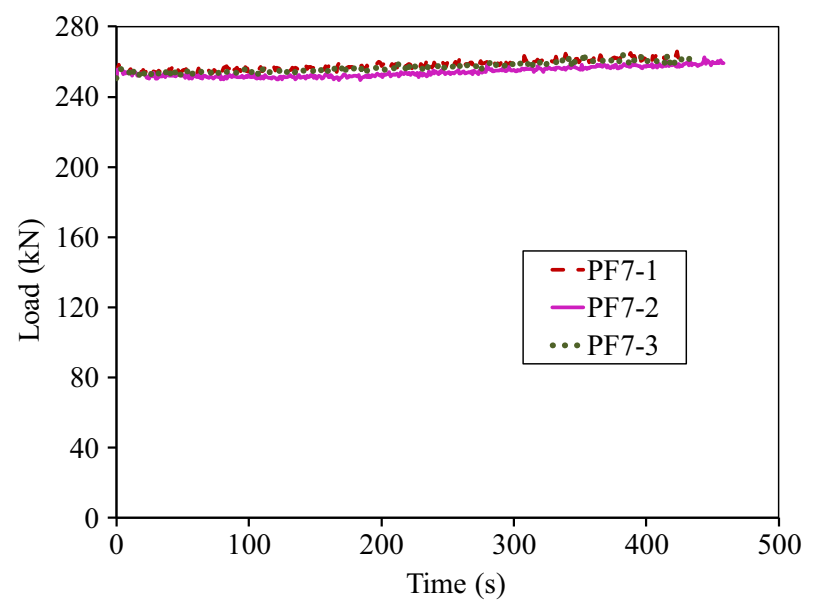

\section{Figure 6. Load against time for specimen PF7.}

pacting, and so the influence of RTPF on the fresh concrete's workability was low. The average compressive strength of the RTPF concrete, for Series 1, ranged from $65 \mathrm{MPa}$ to $67 \mathrm{MPa}$. For the highest fibre dosage $\left(7 \mathrm{~kg} / \mathrm{m}^{3}\right)$, the compressive strength was around $6 \%$ lower than that of the corresponding plain concrete (Plain1).

Specimen SFC, containing just $40 \mathrm{~kg} / \mathrm{m}^{3}$ of RTSF, had a slightly higher average compressive strength of $73 \mathrm{MPa}, 4.5 \%$ higher than that of the corresponding plain concrete (Plain2). An increase in strength due to the addition of steel fibres could be caused by the lateral restraint which they provide, which tends to increase the ductility of concrete [33,34]. RTSF concrete specimens with the addition of $2 \mathrm{~kg} / \mathrm{m}^{3}$ and $5 \mathrm{~kg} / \mathrm{m}^{3}$ of RTPF (SF40PF2 and SF40PF5) show a small reduction $(<5 \%)$ in compressive strength, probably due to an increase in the air entrapped during RTPF integration.

The above-mentioned compressive strength data is the mean value of the three compressive test cubes for each spalling test specimen. The standard deviation of each set of three cubes ranges from 0.5 to $3 \mathrm{MPa}$.

\subsection{Spalling Test Results}

The applied load $(250 \mathrm{kN}$ ) increased only slightly (up to $5 \%$ ) during the tests, as exemplified in Fig. 6 for specimen FP7, due to the restraint to thermal expansion provided by the reaction frame.

Images of the exposed surfaces for Series 1 and 2 of the spalling tests are shown in Tables 4 and 5, respectively. For Series 1, two (Plain1-1 and Plain1-3) of the three plain concrete specimens and two (PF1-2 and PF1-3) of the three specimens with low RTPF dosage $\left(1 \mathrm{~kg} / \mathrm{m}^{3}\right)$ experienced explosive spalling. In particular, specimens Plain1-1, PF1-2 and PF1-3 spalled severely. None of the specimens with RTPF doses higher than $1 \mathrm{~kg} / \mathrm{m}^{3}$ (PF2 and PF7) spalled. PF2-1 failed at ambient temperature in a trial loading test. For Series 2, two (Plain2-1 and Plain2-2) of the 


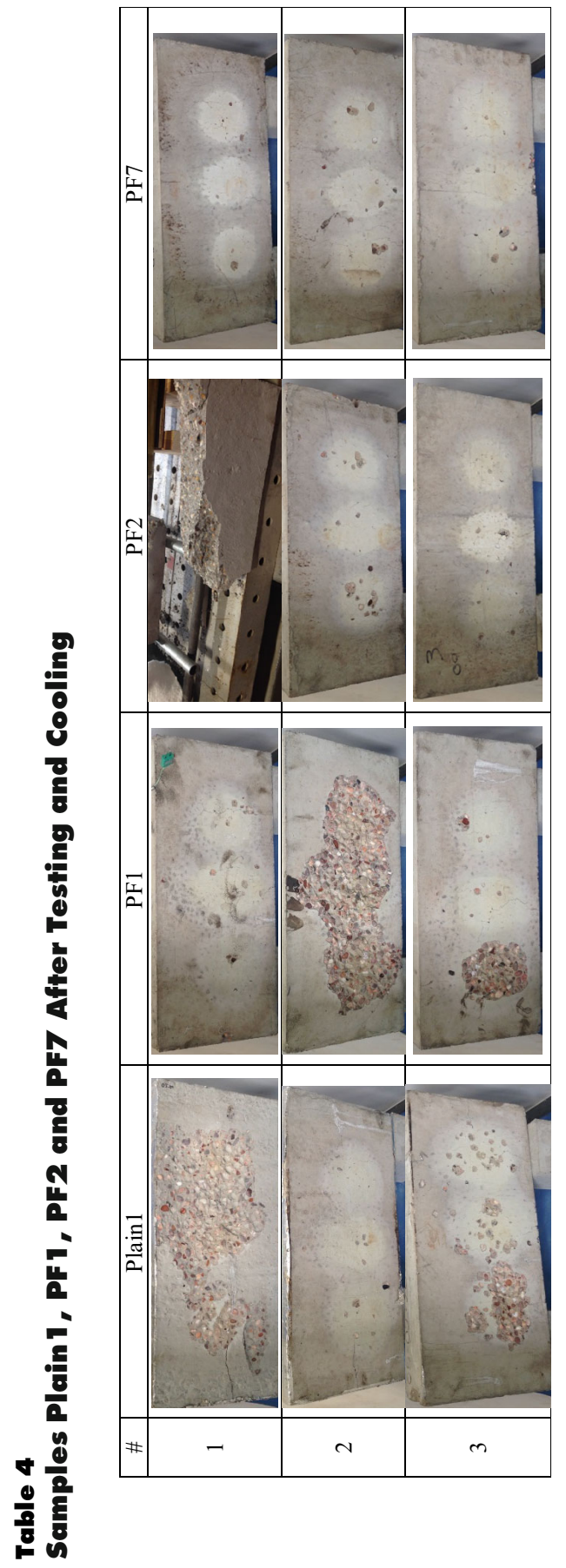




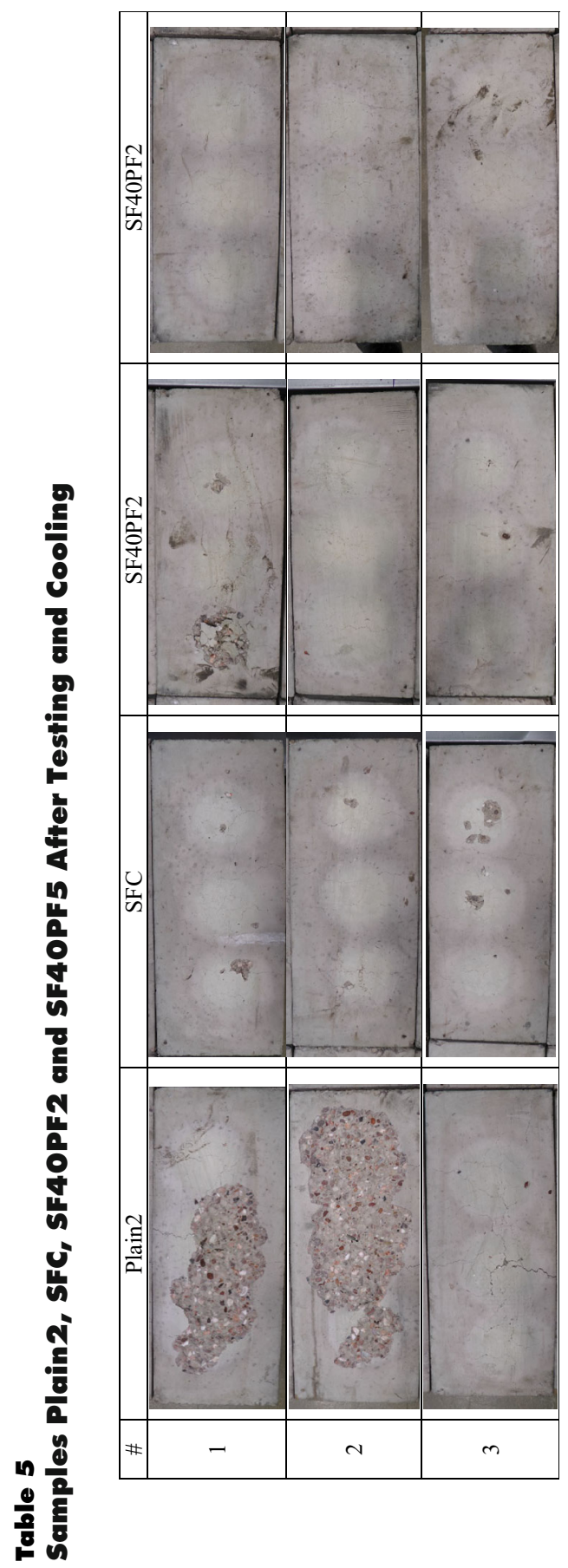




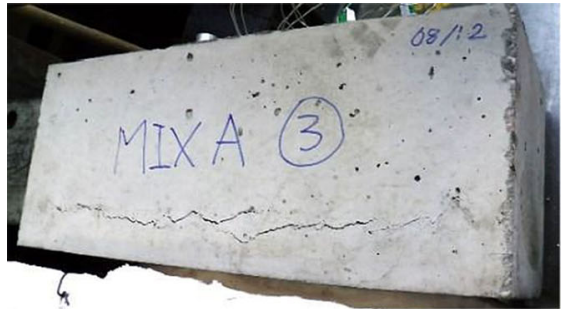

(a)

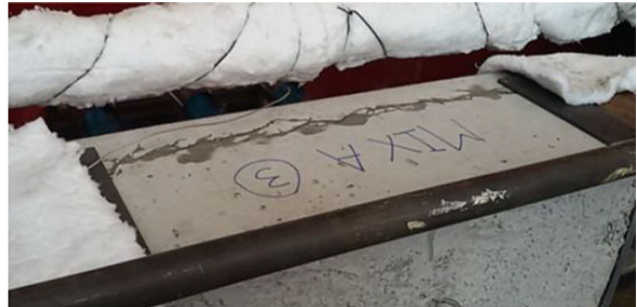

(b)

Figure 7. (a) Large crack on top of specimen Plain2-3. (b) Water/vapour escaping from the crack during test.
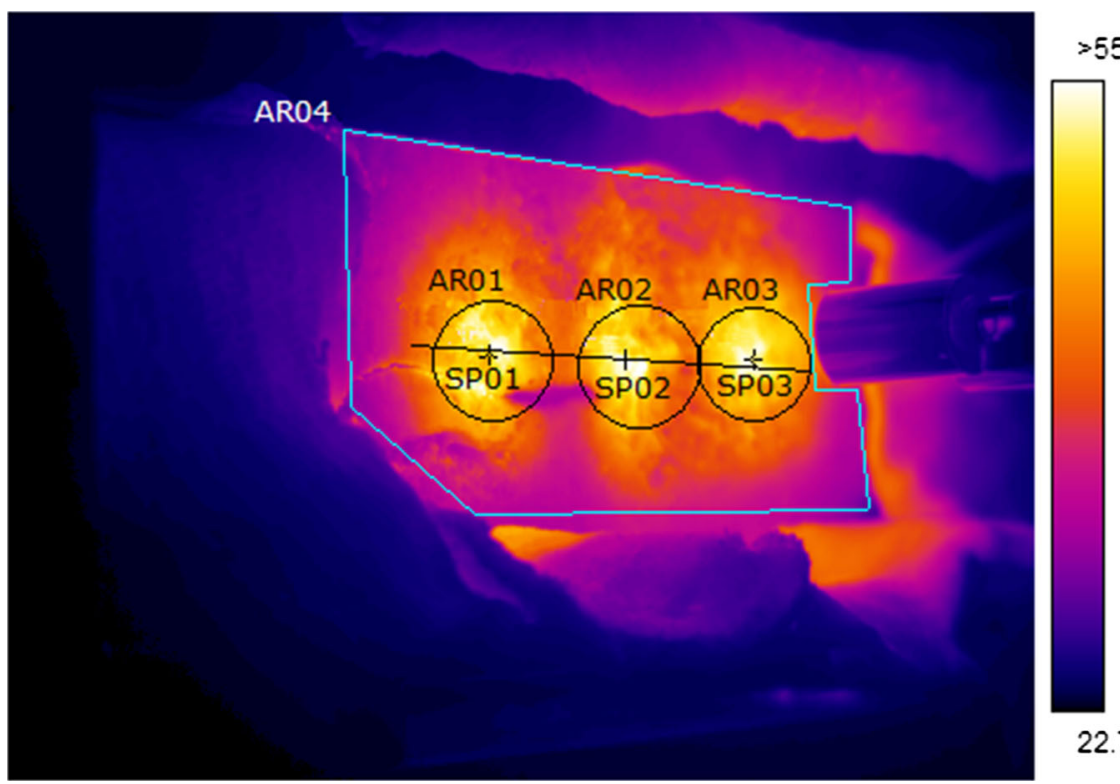

$22.7^{\circ} \mathrm{C}$

Figure 8. Surface temperature measured by thermal imaging camera.

three plain concrete specimens experienced severe spalling, with a maximum spalling depth of $14 \mathrm{~mm}$. The other plain concrete specimen (Plain2-3) did not spall, but a large splitting crack occurred on the top face (Fig. 7). This may have caused a reduction in pore pressure and prevented the explosive spalling from happening. None of the specimens with RTSF, except SF40PF2-1, experienced spalling, showing that RTSF may also contribute to the reduction of the risk of fire spalling; however, more research is required to confirm this tentative conclusion. RTSF, which is composed of finer fibres (of $0.1 \mathrm{~mm}$ to $0.2 \mathrm{~mm}$ diameter and $20 \mathrm{~mm}$ 


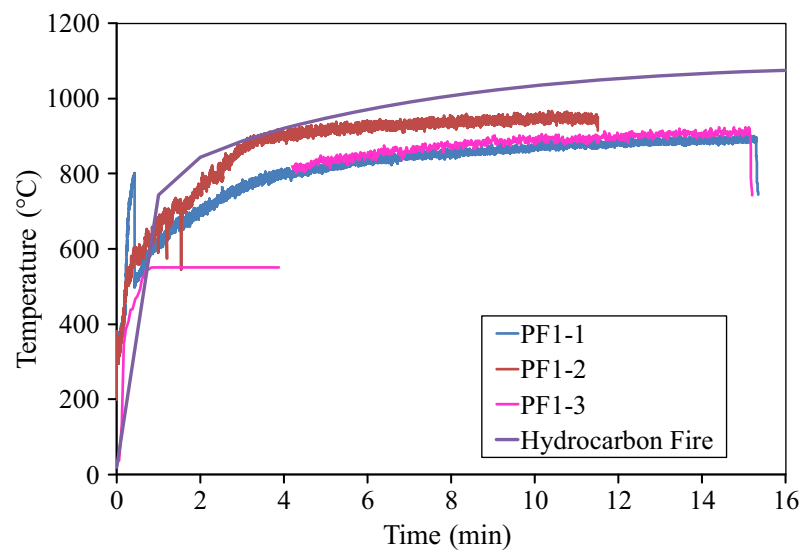

Figure 9. Maximum surface temperature against time of the slab for samples using the IR camera.

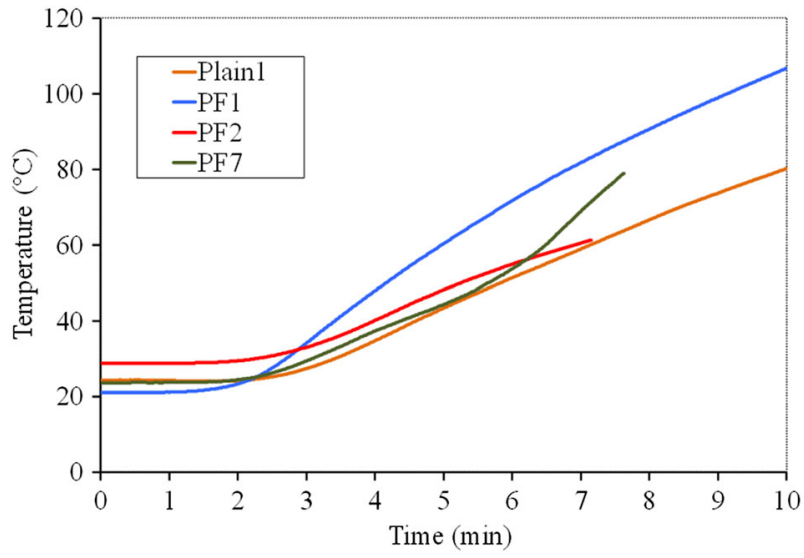

Figure 10. Temperatures measured by the internal thermocouples at the centres of the specimens and $50 \mathrm{~mm}$ behind the heated surface.

average length) is distinctly different from the typical manufactured fibres (of $0.4 \mathrm{~mm}$ to $0.5 \mathrm{~mm}$ diameter and $35 \mathrm{~mm}$ length) used for tunnel applications, leading to larger numbers of fibres per unit volume of concrete, and hence a denser fibre distribution. Moreover, the irregular geometry of RTSF enhances the bond between concrete and fibres. SF40PF2-1, one of the three specimens with RTSF and $2 \mathrm{~kg} / \mathrm{m}^{3}$ of RTPF spalled, but the spalled concrete was held in place by the steel fibres and remained attached to the specimen surface. This shows that RTSF might also contribute by keeping the spalled concrete on the heated surface and retaining its thermal insulation to the steel reinforcement. 


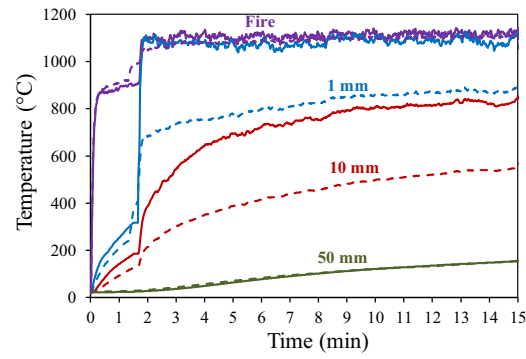

(a)

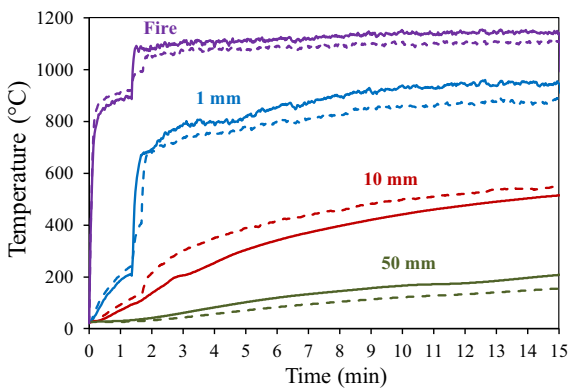

(b)

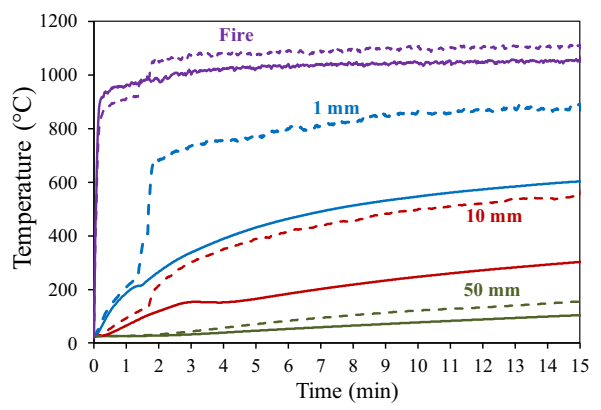

(c)

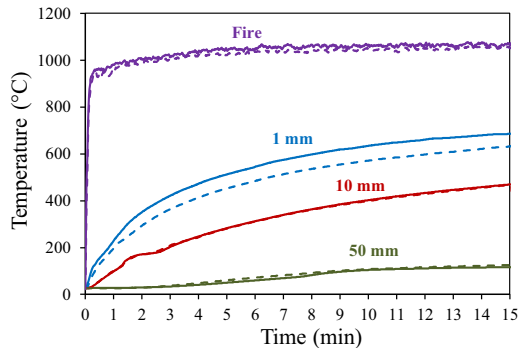

(d)

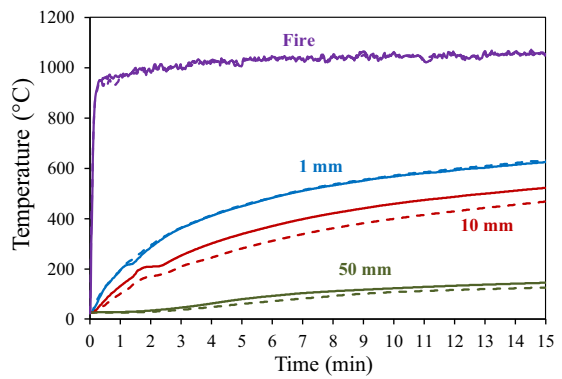

(e)

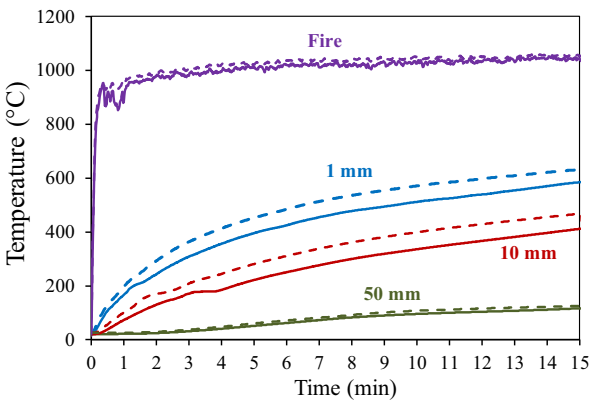

(f)

Figure 11. Temperature against time of thermocouples for specimens Plain2 and SFC. Dashed lines are average temperatures per each set of three repeating specimens. (a) Plain2-1, (b) Plain2-2, (c) Plain23, (d) SFC-1, (e) SFC-2, (f) SFC-3.

3.3.1. Series 1: Temperature Measurement Figure 8 shows a typical infrared (IR) camera image and the specific points and areas used for data analysis. The location, measuring angle and focus of the IR camera are identical for all tests. The accuracy of the IR camera is $\pm 1 \%$ of reading.

Figure 9 shows the maximum surface temperature plotted against time, determined from one of the three areas AR01, AR02 and AR03 (see Fig. 8) directly heated by the blowtorch for the three specimens of PF1. The specimens experienced a high initial heating rate, which then reduced after a few minutes. This 


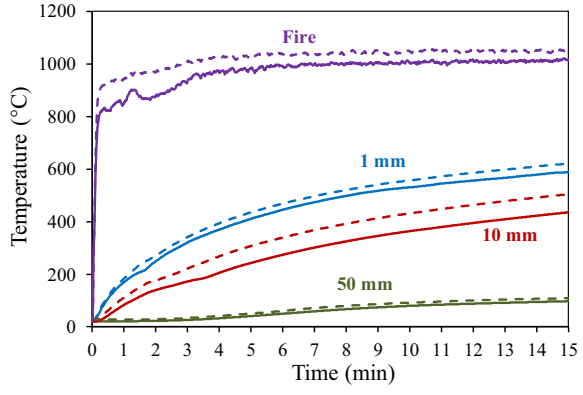

(a)

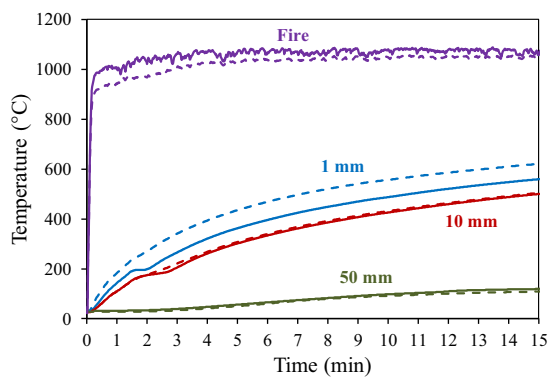

(b)

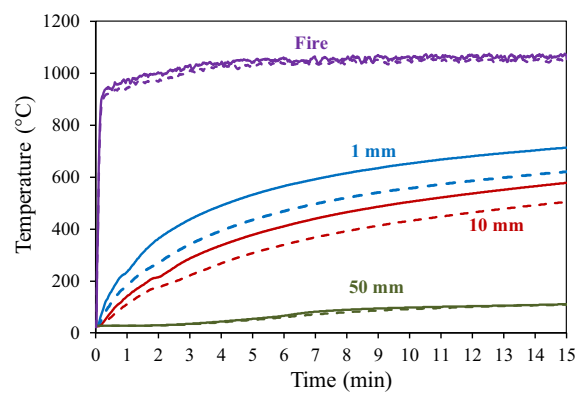

(c)

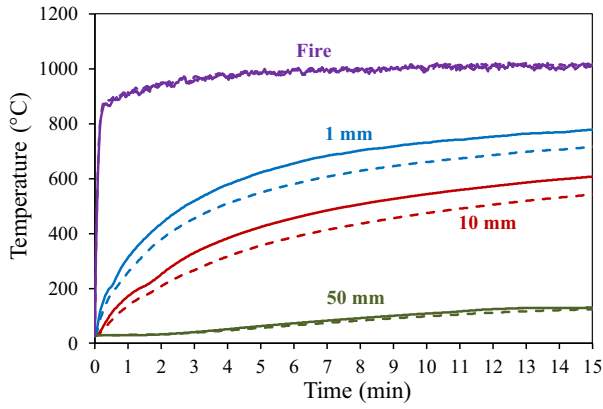

(d)

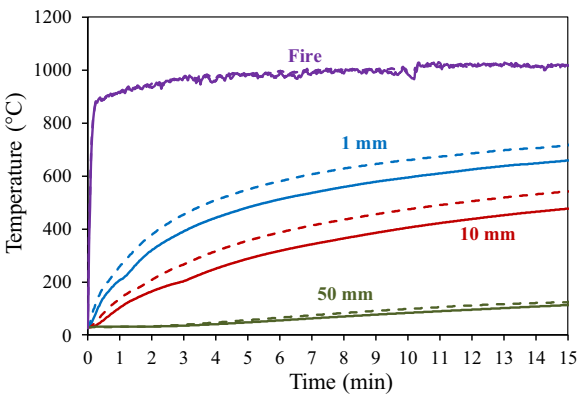

(e)

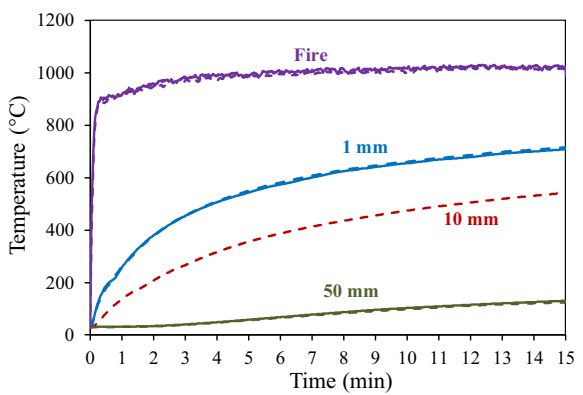

(f)

Figure 12. Temperature against time of thermocouples for specimens SF4OPF2 and SF4OPF5. Dashed lines are average temperatures per each set of three repeating specimens. (a) SF4OPF2-1, (b) SF4OPF22, (c) SF40PF2-3, (d) SF4OPF5-1, (e) SF40PF5-2, (f) SF40PF5-3.

maximum temperature is used to calculate the heating rate, which is then compared with the heating rate of the PD 7974-1 large hydrocarbon pool fire curve [31]. The comparison indicates a reasonable match between the two. It is worth noting that the maximum surface temperature of the severely spalled specimen 
(PF1-2) dropped suddenly when spalling occurred, revealing the temperature on the now-exposed cooler inner layer of concrete.

The temperatures measured by the internal thermocouples (see Fig. 10) show smooth curves of increasing temperature with time. These smooth curves indicate a steady heating rate, without large variations in temperature. As the surface heating of the specimens was consistent between tests this means that each mix has a similar thermal gradient.

3.3.2. Series 2: Thermocouples The thermocouple measurements are plotted for Plain2 and SFC in Fig. 11, and for SF40PF2 and SF40PF5 in Fig. 12. For Plain21, Fig. 11a shows clearly that the concrete temperatures at depths of $1 \mathrm{~mm}$ and $10 \mathrm{~mm}$ from the heated surface suddenly increase when spalling occurs. This is because both thermocouples are then directly exposed to the fire due to the spalling, and so they no longer measure the inner concrete temperature, but that of the fire. A similar phenomenon can be observed in specimen Plain2-2, which also spalled. The fire temperatures for these two spalled specimens (Fig. 11a, b), measured by a thermocouple (Fig. 4d) placed at the heated surface, are higher than those of the other tests. This is because the impact due to the explosive spalling dislocated the surface thermocouple and pushed it towards the part of the flame which is at a higher temperature. It is worth noting that for all concrete mixes a short temperature plateau could be observed at around $200^{\circ} \mathrm{C}$ at $10 \mathrm{~mm}$ below the heated surface. The phase change from water to gas (vaporization) is an endothermic transformation, so that the system absorbs energy from its surroundings; in this case using some of the heating energy. The effect is to temporarily reduce the heat transfer into the concrete, causing the short temperature plateau observed. The temperature at which this plateau occurs depends on the concrete compaction. Previous researchers [35] have reported a similar phenomenon and speculated that it may be caused by the capillary forces that exist in pores at the interface between liquid water, gas phase and solid.

Although none of the specimens SFC and SF40PF2, with RTSF, experienced explosive spalling, the temperatures at $10 \mathrm{~mm}$ below the heated surface of the SFC specimens also show a short plateau at around $200^{\circ} \mathrm{C}$.

It can be seen that the thermocouple measurements at common depths vary between the three repeated specimens. This is rather expected since, although prefixed, the thermocouples might have moved during casting and so their locations might vary; also, any concrete cracking could affect the thermocouple measurements, especially for those close to the heated surface.

\section{Thermal Analysis}

The temperature profiles obtained experimentally were compared with numerical predictions obtained using the Vulcan Thermal analysis software, developed at the University of Sheffield [36]. Vulcan Thermal has the ability to carry out thermal analysis on concrete, adopting a two-dimensional non-linear finite element procedure to predict the temperature distributions within the cross-sections of concrete 
members subjected to user-specified time-temperature fire curves [37]. The thermal properties of concrete vary with temperature, and the influence of moisture initially held within concrete is included in the model.

Two specimens, SFC-1 and SF40PF5-2, were modelled in this study. These specimens were chosen since they did not spall, and the internal thermocouple readings are considered reasonably accurate.

The boundary conditions of the model were set as "face to fire" at the bottom and insulated at the top and sides. The fire curve used was taken from the surface thermocouple measurements obtained from each of the tests. A sensitivity analysis was carried out to investigate the effect of the variation of thermal parameters such as the emissivity of the concrete surface and the surface absorption factor. The parameters used in the thermal analysis are presented in Table 6. The other thermal properties of concrete were taken according to EC2 [38].

The thermal analysis results are compared in Fig. 13. The results show a good match between the time-temperature curves from the explosive spalling tests and Vulcan thermal analysis, which could be used as the basis for the future development of a thermos-hygro-mechanical spalling predictive model.

\section{Table 6}

Parameters Used in the Analysis

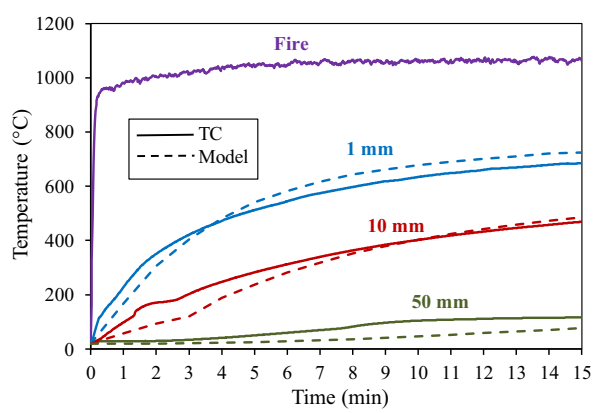

(a)

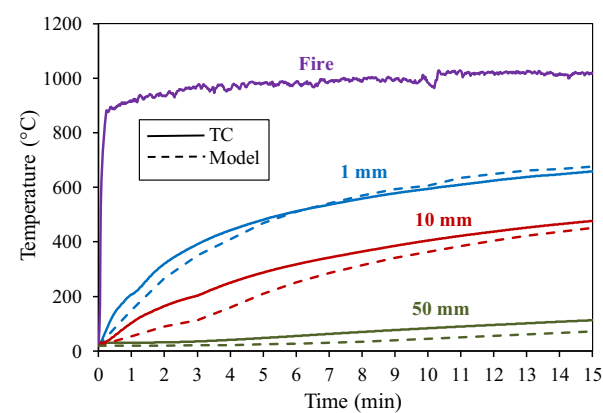

(b)

Figure 13. Time-temperature curve of specimens at different depths (numerical results vs. thermocouples) (a) SFC-1, (b) SF40PF5-2. 


\section{Conclusions}

The paper has shown promising initial experimental results, indicating the potential of using recycled tyre fibres to replace manufactured fibres for the development of more sustainable concretes which resist fire-spalling. It was found that recycled tyre polymer fibres have the potential to prevent fire-spalling. The addition of RTPF had little influence on either the fresh or hardened properties of concrete but increased slightly the moisture loss during drying. The recycled tyre steel fibres could also contribute to a reduction of the risk of fire-induced spalling, possibly due to their unique dimensions and geometry. RTSF could also prevent serious damage due to fire spalling by keeping the spalled concrete attached to the heated surface, and thus retaining thermal insulation to the steel re-bars. The above conclusions are drawn based on preliminary experiments subject to the testing conditions reported in this paper. Before more general conclusions can be drawn, further research is necessary and is currently being undertaken to confirm the effectiveness of RTSF and RTPF in preventing spalling, to quantify the optimum dosage of these fibres, to understand the mechanisms of spalling, to quantify spalling resistance, and eventually to develop design guidance for the use of RTSF and RTPF for spalling prevention.

\section{Acknowledgements}

The research leading to these results has received funding from the European Union Seventh Framework Programme (FP7/2007-2013) under grant agreement No. 603722 and from the European Union's Horizon 2020 research and innovation programme under the Marie Sklodowska-Curie grant agreement No. 699875. This work was also supported by the Engineering and Physics Sciences Research Council (EP/N019555/1) and the Newton Fund and Innovate UK (102715). The authors also gratefully acknowledge the contribution of Grace Waterman and Shun Hey Dawn Hou to the experimental work.

\section{Open Access}

This article is distributed under the terms of the Creative Commons Attribution 4.0 International License (http://creativecommons.org/licenses/by/4.0/), which permits unrestricted use, distribution, and reproduction in any medium, provided you give appropriate credit to the original author(s) and the source, provide a link to the Creative Commons license, and indicate if changes were made.

\section{References}

1. SP Technical Research Institute of Sweden (2012) Fire-spalling of self-compacting concrete. https://www.tunneltalk.com/TunnelTech-May12-Concrete-fire-spalling.php. Accessed 10 Sept 2018 
2. Dwaikat MB, Kodur VKR (2009) Hydrothermal model for predicting fire-induced spalling in concrete structural systems. Fire Saf J 44:425-434

3. Jansson R (2013) Fire spalling of concrete - a historical overview. EDP Sciences, Borås

4. Kato M, Dobashi H, Tajima H, Kawada N, Takahama T (2015) The application of fireproof SFRC segments and cast-in-place fireproof concrete to metropolitan expressway Yokohama circular northern route. M. E. Obayashi Corporation, Ed

5. Lourenço L, Barros J, Alves JA (2011) Fibre reinforced concrete of enhanced fibre resistance for tunnel segments. ACI 276:1-34

6. Nishida A, Yamazaki N, Inoue H, Schneider U, Diederichs U (1995) Study on the properties of high strength concrete with short polypropylene fibers for spalling resistance. Proc Symp Concr Under Sev Environ 2:1141-1150

7. Kalifa P, Chéné G, Gallé C (2001) High-temperature behaviour of HPC with polypropylene fibres from spalling to microstructure. Cem Concr Res 31:1487-1499

8. Noumowé A (2005) Mechanical properties and microstructure of high strength concrete containing polypropylene fibres exposed to temperatures up to $200^{\circ} \mathrm{C}$. Cem Concr Res 35:2192-2198

9. Zeiml M, Leithner D, Lackner R, Mang HA (2006) How do polypropylene fibers improve the spalling behavior of in situ concrete?. Cem Concr Res 36:929-942

10. Ozawa M, Morimoto H (2014) Effects of various fibres on high-temperature spalling in high-performance concrete. Constr Build Mater 71:83-92

11. Richardson A (2006) Compressive strength of concrete with polypropylene fibre additions. Struct Surv 24(2):138-153

12. Doherty P, Ali F, Nadjai A, Choi S (2012) Explosive spalling of concrete columns with steel and polypropylene fibres subjected to severe fire. FireSert, SCOBE, University of Ulster

13. Rickard I, Maluk C, Robert F, Bisby LA, Deeny SM, Tessier C (2015) Development of a novel small-scale test method to investigate heat-induced spalling of concrete tunnel linings. In: 4th international workshop on concrete spalling (IWCS) due to fire exposure, At Leipzig, Germany

14. Thomas J, Ramaswamy A (2007) Mechanical properties of steel fiber-reinforced concrete. J Mater Civ Eng 19(5):385-392

15. Peng GF, Yang WW, Zhao J, Liu YF, Bian SH, Zhao LH (2006) Explosive spalling and residual mechanical properties of fiber-toughened high-performance concrete subjected to high temperatures. Cem Concr Res 36:723-727

16. Vairagade VS, Kene KS (2013) Strength of normal concrete using metallic and synthetic fibers. Procedia Eng 51:132-140

17. Yermak N, Pliya P, Beaucour AL, Simon A, Noumowé A (2017) Influence of steel and/or polypropylene fibres on the behaviour of concrete at high temperature: spalling, transfer and mechanical properties. Constr Build Mater 132:240-250

18. CEN (2002) Eurocode 1: actions on structures-Part 1-2: general actions - actions on structures exposed to fire. European Committee on Standardization, Brussels

19. Rivaz B (2006) Technical performance of reinforced concrete with steel fibers and polymers. Tunn Ouvrages Souterr 198:367-371

20. Kahanji C, Ali F, Nadjai A (2016) Explosive spalling of ultra-high performance fibre reinforced concrete beams under fire. J Struct Fire Eng 7(4):328-348

21. Serdar M, Baricevic A, Rukavina MJ, Pezer M, Bjegovic D, Stirmer N (2015) Shrinkage behavior of fibre reinforced concrete with recycled tyre polymer fibres. Int $\mathrm{J}$ Polym Sci 2015:145918

22. Pilakoutas K, Neocleous K, Tlemat H (2004) Reuse of tyre steel fibres as concrete reinforcement. Proc ICE Eng Sustain 157(3):131-138 
23. Anagennisi-Innovative Reuse of All Tyre Components in Concrete. http://anagennisi. org. Last accessed 10 June 2017

24. Lourenço L, Barros J, Alves A (2011) Fiber reinforced concrete of enhanced fire resistance for tunnel segments. ACI Special Publication, American Concrete Institute, Michigan, pp. 1-34

25. Baričević A, Bjegović D, Skazlić M (2017) Hybrid-reinforced concrete with unsorted recycled fiber-reinforced concrete with unsorted recycled-tire steel fibers. J Mater Civ Eng 29(6):06017005

26. Bartolac M, Damjanović D, Duvnjak I (2015) Punching strength of flat slabs with and without shear reinforcement. Građev J Croat Assoc Civil Eng 67(8):771-786

27. Khoury G (2000) Effect of fire on concrete and concrete structures. Prog Struct Materials Eng 2(4):429-447

28. Twincon Ltd. Tyre wire in concrete. http://www.twincon.co.uk/. Last accessed 17 July 2017

29. BS EN 12390-3-2009 (2009) Testing hardened concrete, part 3: compressive strength of test specimens. British Standards Institution, London

30. Jafarifar N, Pilakoutas K, Bennett T (2014) Moisture transport and drying shrinkage properties of steel-fibre-reinforced-concrete. Constr Build Mater 73:41-50

31. PD 7974-1 (2003) The application of fire safety engineering principles to the design of buildings - part 1: initiation and development of fire within the enclosure of origin (sub-system 1). British Standards Institution, London

32. Sideris KK, Manita P (2013) Influence of length and dosage of polypropylene fibres on the spalling tendence and the residual properties of self-compacting concrete after heated at elevated temperatures. EDP Sciences, Borås

33. Shin HO, Yoon YS, Lee SH, Cook WD, Mitchell D (2015) Effect of steel fibers on the performance of ultrahigh-strength concrete columns. J Mater Civ Eng 27(4):04014142

34. Nardinocchi A, Corinaldesi V (2016) Influence of type of fibers on the properties of high performance cement-based composites. Constr Build Mater 107:321-331

35. Mindeguia J, Pimienta P, Noumowé A, Kanema M (2010) Temperature, pore pressure and mass variation of concrete subjected to high temperature-experimental and numerical discussion on spalling risk. Cem Concr Res 40:477-487

36. Yu C, Burgess IW, Huang Z, Plank RJ (2006) The development of finite elements for finite elements for 3D structural analysis in fire. http://fire-research.group.shef.ac.uk/ste elinfire/downloads/CMY_bisteel_06.pdf. Accessed 17 Apr 2016

37. Huang ZH (2010) The behaviour of reinforced concrete slabs in fire. Fire Saf $\mathbf{J}$ 45(5):271-282

38. CEN (2004) Eurocode 2: design of concrete structures - part 1-2: general rules - structural fire design. European Committee on Standardization, Brussels

Publisher's Note Springer Nature remains neutral with regard to jurisdictional claims in published maps and institutional affiliations. 